\title{
Review of the Cosolvency Models for Predicting Drug Solubility in Solvent Mixtures: An Update
}

\author{
Abolghasem Jouyban \\ Pharmaceutical Analysis Research Center and Faculty of Pharmacy, Tabriz University of Medical Sciences, \\ Tabriz, Iran.
}

Received, July 28, 2019; Revised, September 4, 2019; Accepted, September 17, 2019; Published, September $22,2019$.

\begin{abstract}
The cosolvency models frequently used in solubility data modeling of drugs in mixed solvents were reviewed and their accuracies for calculating the solubility of solutes were briefly discussed. The models could be used either for correlation of the generated solubility data with temperature, solvent composition etc or for prediction of unmeasured solubility data using interpolation/extrapolation technique. Concerning the correlation results employing a given number of independent variables, the accuracies of the investigated models were comparable, since they could be converted to a single mathematical form, however, the accuracies were decreased when models emplyed more independent variables. The accurate correlative models could be employed for prediction purpose and/or screening the experimental solubility data to detect possible outliers. With regard to prediction results, the best predictions were made using the cosolvency models trained by a minimum number of experimental data points and an ab initio accurate prediction is not possible so far and further mathematical efforts are needed to provide such a tool. To connect this gap between available accurate correlative models with the ab initio predictive model, the generally trained models for calculating the solubility of various drugs in different binary mixtures, various drugs in a given binary solvent and also a given drug in various binary solvents at isothermal condition and/or different temperatures were reported. Available accuracy criteria used in the recent publications were reviewed including mean percentage deviation (MPD). The MPD for correlative models is $1-10 \%$ whereas the corresponding range for predictive models is $10-80 \%$ depend on the model capability and the number of independent variables employed by the model. This is an update for a review article published in this journal in 2008 .
\end{abstract}

\section{INTRODUCTION}

Solubility is an important issue in the pharmaceutical industry and still is considered as a topic under investigation $(1,2)$, since forty percent of the marketed compounds are poorly soluble and approximately ninety percent of under development drugs can be categorized as poorly soluble (3). Solubility of a drug is the simplest phenomenon in pharmaceutical investigations and is required in many applications in the industry including; solubilization of a drug, crystallization from solutions, preparation of liquid drug formulations, preparation of nano-particles etc. Low aqueous solubility of drugs could also cause crystalluria and is a limitation in clinical application of drugs (4) or may cause beneficial effect such as prolongation of drug action in the target tissue (5). Among various solubilization methods, cosolvency is the most common and feasible method. Aqueous-organic solvent mixtures could be used in the formulation of liquid dosage forms, in solution preparation and/or crystalization processes. The solubility data in cosolvent + water mixtures could also be used in preparation of nanosuspensions of the pharmaceuticals using the bottom-up technique (6). Non-aqueous solvent mixtures are also widely used in the pharmaceutical industry in crystallization, synthesis media, nanoparticle formation or preparation of non-aqueous solutions of drugs.

The experimental determination of drug's solubility is still the most reliable method for obtaining accurate and valid data (7). Various methods were reported for drug solubility determination which were reviewed in previous works $(8,9)$. The experimental determination is a time consuming and costly procedure and alternative methods are in demand. Smart and automated solubility determination methods (9) could be considered as an applicable alternative.

Corresponding Author: A. Jouyban, Pharmaceutical Analysis Research Center and Faculty of Pharmacy, Tabriz University of Medical Sciences, Tabriz 51664, Iran, Email: ajouyban@hotmail.com 
The mathematical models were also proposed to validate the accuracy of measured solubility data or facilitate the prediction of the solubility data at other temperatures and/or solvent compositions.

From a practical application and ease of use viewpoints, the models vary from the simplest log-linear model of Yalkowsky (10) to the complex model of Ruckenstein and Shulgin (11). It is obvious that, simple models are more preferred in pharmaceutical applications of the models.

The pioneers of solubility data modeling include; Joel H. Hildebrand (1881-1983) who introduced the Hildebrand solubility approach (12) which is applicable only to the solubility of non-polar solutes in non-polar solvents. Its extended versions were reported to provide better predictions for pharmaceutical systems including methods based on solubility parameters developed by Alfred N. Martin (1919-2003) and his coworkers (13). The linear solvation energy relationship models proposed by Michael $\mathrm{H}$. Abraham are the most accurate models to predict the solubility of a solute in the mono-solvent systems (14). The Abraham solvent coefficients which derived from experimental solubility data are available for a limited number of solvents, however, they are not available for some pharmaceutically relevant cosolvents like polyethylene glycols. The model provides solubility values with relatively high prediction error, however, it possesses an advantage of in silico prediction of aqueous solubility of drugs and no experimental data is required as input data. Another predictive model was developed by Samuel H. Yalkowsky is the general solubility equation (15) for aqueous solubilities which requires the melting point and $\log \mathrm{P}$ of the drug as input data. The $\log \mathrm{P}$ values could be computed using software such as ACD with reasonable accuracy.

Anthony N. Paruta and co-workers (16) correlated the solubility of drugs to the dielectric constant of the mixed solvent system. The loglinear model of Yalkowsky (10) was the next model providing a simple equation to calculate the solubility of drugs in cosolvent + water mixtures and the constants of this model were reported for most of pharmaceutically relevant cosolvents. The model requires experimental aqueous solubility data along with its $\log \mathrm{P}$ as input data. The extended Hildebrand solubility approach of Martin et al. (13, 17-18) and further extensions of this approach made by Pilar Bustamante and her co-workers $(19,20)$ were the other versions of the cosolvency models. The excess free energy models of Gordon L. Amidon and his colleagues (21) was provided more accurate predictions by including experimental solubility data in the mono-solvents and also molar volumes of water, cosolvent and the drug. Kenneth A. Connors and his co-workers (22) proposed a phenomenological model derived from the free energy changes of the processes involved in the dissolution of a solute in the solvent system. The combined nearly ideal binary solvent/Redlich-Kister (CNIBS/R-K) equation was derived by William E. Acree $\operatorname{Jr}(23)$ and provided the most accurate solubility calculations in comparison with the above mentioned models. The general cosolvency model was reported by Mohammad Barzegar-Jalali and his co-workers (24), which is derived from above mentioned models. During last twenty years, the applications of the CNIBS/R-K equation was extended to represent solvent composition and temperature effects on solute solubility and applied to other physico-chemical properties (PCPs) of mixed solvent systems (25-37) and re-named as the Jouyban-Acree model. The model provided reasonably accurate predictions employing experimental data in mono-solvents and a number of data in mixed solvents at various temperatures. Further works on computational methods and also determination of drug solubilities in mixed solvents are ongoing in our research group.

Although considerable progresses were made in computer sciences and sophisticated software and powerful hardware are available, it must be frankly stated that we are still not able to predict the solubility of drugs as stated by Hildebrand in the last century: "There is scarcely anything more important for a chemist than a knowledge of solubilities, but unfortunately he finds it more difficult to predict how soluble a substance will be in a given solvent than it is to predict almost any other important property.". No accurate prediction tool is available for solubility of drugs in water, organic solvents or mixed solvent systems (7, 38, 39). More experimental and computational efforts are demanded to provide such a tool. It is obvious that the quality of the experimental data is an important factor in providing accurate models (40-42). To achieve this valuable task, more comprehensive solubility database in mono- and mixed solvents should be generated by the research groups around the world and also more comprehensive and preferably theoretical predictive tools should be provided. Available solubility data of solutes in water (43) and the solubility of pharmaceuticals in 
organic mono-solvents and mixed solvents (1) were compiled as separate handbooks.

A simple search using "( TITLE ( solubili*) AND TITLE-ABS-KEY ( model) AND TITLE ( mix* ) )" as search words in Scopus database (44), resulted in 720 papers. Figure 1 illustrated the relative frequency of the employed solubility models in the published works in 2008-2018.

\section{MODELS REPRESENTING SOLUBILITY DATA IN A GIVEN SOLVENT AT VARIOUS TEMPERATURES}

The van't Hoff equation is extensively used to correlate the logarithm of solute's mole fraction solubility $\left(\ln x_{\mathrm{T}}\right)$ to the reciprocal of absolute temperature $\left(\frac{1}{T}\right)$ (45). The van't Hoff equation is:

$$
\ln x_{\mathrm{T}}=A+\frac{B}{T}=\frac{\Delta S_{d}^{\mathrm{o}}}{R}-\frac{\Delta H_{d}^{\mathrm{o}}}{R T}
$$

where $x_{\mathrm{T}}$ is the solubility at a given solvent composition at various temperatures, $A$ and $B$ are the constants computed from correlation of the experimental solubility data. $\Delta H_{d}^{\circ}$ is the molar enthalpy of dissolution, $\Delta S_{d}^{0}$ refers to molar entropy of dissolution and $R$ is the gas constant. These coefficients reflect the variations in activity coefficients and indicate the effect of solution non-ideality on the solubility.

Hildebrand equation presents $\ln x_{\mathrm{T}}$ as a linear function of $\ln T$ as:

$$
\ln x_{\mathrm{T}}=A^{\prime}+B^{\prime} \ln T
$$

in which $A^{\prime}$ and $B^{\prime}$ are the model constants (46). Grant et al. (47) represented a three parameter equation to provide better correlations. The equation is:

$$
\ln x_{\mathrm{T}}=A^{\prime \prime}+\frac{B^{\prime \prime}}{T}+C^{\prime \prime} \ln T
$$

in which $A^{\prime \prime}, B^{\prime \prime}$ and $C^{\prime \prime}$ are the model constants. The model was derived from van't Hoff relation by employing apparent partial molar enthalpy of solution $\left(\Delta H^{*}\right)$ instead of the partial molar enthalpy of solution ( $\Delta H$ ) and $\Delta H^{*}$ was assumed as a linear function of temperature as:

$$
\Delta H^{*}=\alpha+\beta T
$$

in which $\alpha$ could be considered as the hypothetical value of $\Delta H^{*}$ at $\mathrm{T}=0 \mathrm{~K}$ and $\beta$ as the change in the apparent partial molar heat capacity of the solute at a constant pressure $\left(\Delta C_{p}\right)$. Equation 3 was represented by Apelblat and Manzurola in 1999 (48) and is commonly used in the recent literature as Apelblat equation (49-53). Both Hildebrand and van't Hoff equations provide accurate calculations especially at a narrow temperature range which is commonly used in the pharmaceutical applications. However, Grant et al. (47) recommended when more than five data points covering a relatively wide temperature range are available, it is better to use Eq. 3. The main advantage of the Hildebrand and van't Hoff equations over Apelblat equation is their linear patterns which make them more reliable for prediction of the solubility at various temperatures using interpolation and/or extrapolation techniques.

The Buchowski model (54) with two adjustable parameters $(\lambda$ and $h)$ correlates the mole fraction solubility of the solute $\left(x_{\mathrm{T}}\right)$ and temperature $T$. It is expressed as:

$$
\ln \left[1+\frac{\lambda\left(1-x_{\mathrm{T}}\right)}{x_{\mathrm{T}}}\right]=\lambda h\left(\frac{1}{T}-\frac{1}{T_{\text {fus }}}\right)
$$

where $T_{\text {fus }}$ refers to the fusion temperature of the solute.

The main limitation of the models correlating the solubility of a drug in a given mono-solvent (or mixed solvent) as a function of temperature is that their trained versions are valid only for the solvent and there is no way to extend the prediction capability to other mono-solvents or solvent compositions. It is obvious that this sort of predictions are required in the pharmaceutical applications when recrystalization processes are designed based on anti-solvent addition and decreasing the temperature of the solution.

\section{COSOLVENCY MODELS ISOTHERMAL CONDITIONS} Semi-theoretical models

The logarithm of the mole fraction solubility of a drug in the solvent mixtures $\left(\ln x_{\mathrm{m}}\right)$ at a constant temperature $T$ and different solvent mass fractions 
can be calculated using the algebraic mixing rule (10):

$$
\ln x_{\mathrm{m}}=w_{1} \ln x_{1}+w_{2} \ln x_{2}
$$

where $w_{1}$ and $w_{2}$ represent the fraction of monosolvents 1 and 2 in binary solvent mixtures in the absence of the drug, $x_{1}$ and $x_{2}$ are the drug solubility in the mono-solvents 1 and 2 . The model could be converted to the log-linear model of Yalkowsky (10) simply by repalcing $w_{2}$ with $\left(1-w_{l}\right)$ and subsequent re-arrangements as:

$$
\begin{aligned}
\ln x_{\mathrm{m}} & =w_{1} \ln x_{1}+\left(1-w_{1}\right) \ln x_{2} \\
& =w_{1} \ln x_{1}+\ln x_{2}-w_{1} \ln x_{2} \\
\ln x_{\mathrm{m}}= & \ln x_{2}+w_{1} \ln x_{1}-w_{1} \ln x_{2} \\
& =\ln x_{2}+w_{1}\left(\ln x_{1}-\ln x_{2}\right)
\end{aligned}
$$

since $\ln x_{2}$ and $\left(\ln x_{1}-\ln x_{2}\right)$ are constant values at a given temperature, one may write the equation as:

$$
\ln x_{\mathrm{m}}=\text { Intercept }+ \text { Slope } \cdot w_{1}
$$

The log-linear model could also be derived from Hildebrand solubility approach as has been shown in an earlier report (55).

The excess free energy models of Williams-Amidon (21) are expressed by:

$$
\ln x_{m}=w_{1} \ln x_{1}+w_{2} \ln x_{2}+A_{1-2} w_{1} w_{2}\left(\frac{V_{s}}{V_{1}}\right)
$$

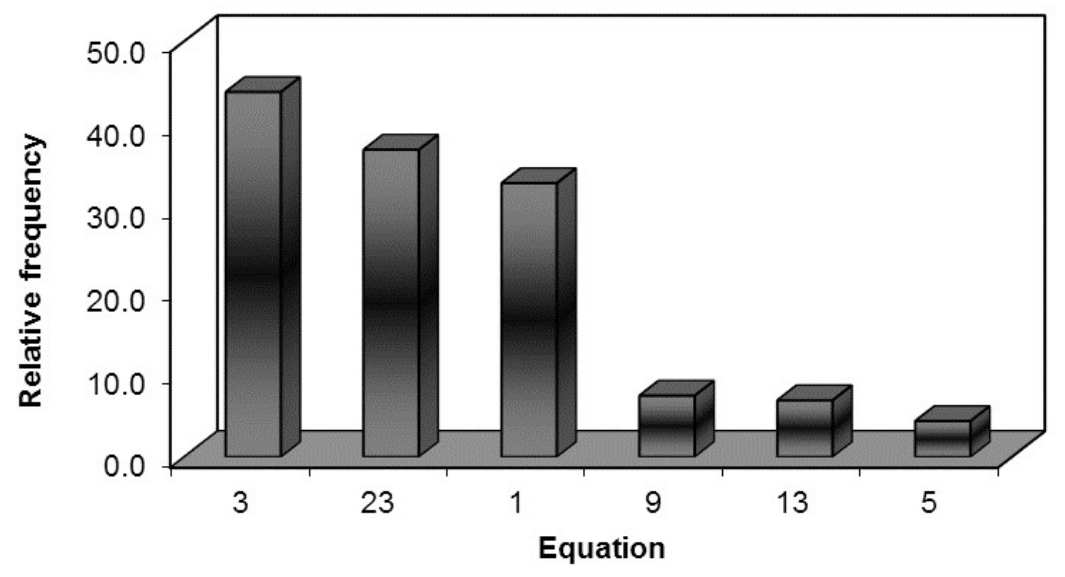

Figure 1. Relative frequency of solubility models employed in recent studies

$$
\begin{aligned}
\ln x_{m}= & w_{1} \ln x_{1}+w_{2} \ln x_{2}-A_{1-2} w_{1} w_{2}\left(2 w_{1}-1\right)\left(\frac{V_{s}}{V_{1}}\right)+2 A_{2-1} w_{1}^{2} f_{2}\left(\frac{V_{s}}{V_{2}}\right)+C_{s} w_{1} w_{2} \\
\ln x_{m}= & w_{1} \ln x_{1}+w_{2} \ln x_{2}-A_{1-2} w_{1} w_{2}\left(2 w_{1}-1\right)\left(\frac{V_{s}}{V_{1}}\right)+2 A_{2-1} w_{1}^{2} w_{2}\left(\frac{V_{s}}{V_{2}}\right)+3 D_{12} w_{1}^{2} w_{2}^{2}\left(\frac{V_{s}}{V_{2}}\right) \\
& +C_{2} w_{1} w_{2}^{2}\left(\frac{V_{s}}{V_{2}}\right)+C_{1} w_{1}^{2} w_{2}
\end{aligned}
$$

where $A_{1-2}, A_{2-1}, C_{s}, D_{12}, C_{2}$ and $C_{1}$ are solvent-solvent or solute-solvent interaction terms, $V_{1}$ and $V_{2}$ represent the molar volumes of solvents 1 and 2, respectively (21).

The CNIBS/R-K was derived from a thermodynamic mixing model and expressed as:

$$
\ln x_{m}=w_{1} \ln x_{1}+w_{2} \ln x_{2}+w_{1} w_{2} \sum_{i=0}^{2} S_{i}\left(w_{1}-w_{2}\right)^{i}
$$


where $S_{i}$ stand for the model constants. The $S_{i}$ terms are computed using either a classical least square analysis (56) or a no intercept least squares analysis (57). The latter numerical method produces more accurate computations for drug's solubility in aqueous binary solvents (57) and is recommended for future applications. The application of Eq. 13 could be extended to calculate the solute solubility in ternary solvent mixtures based on the model parameters obtained from solubility data in the sub-binary solvent systems as $(58,59)$ :

$$
\begin{aligned}
\ln x_{m}= & w_{1} \ln x_{1}+w_{2} \ln x_{2}+w_{3} \ln x_{3}+w_{1} w_{2} \sum_{i=0}^{2} S_{i}\left(w_{1}-w_{2}\right)^{i} \\
& +w_{1} w_{3} \sum_{i=0}^{2} S_{i}^{\prime}\left(w_{1}-w_{3}\right)^{i}+w_{2} w_{3} \sum_{i=0}^{2} S_{i}^{\prime \prime}\left(w_{2}-w_{3}\right)^{i}
\end{aligned}
$$

in which $S_{i}^{\prime}$ and $S_{i}^{\prime \prime}$ are the model constants calculated using solubility data in sub-binary solvent mixtures. One may add ternary solvent interaction terms to provide more accurate calculations (60) as:

$$
\begin{aligned}
\ln x_{m}= & w_{1} \ln x_{1}+w_{2} \ln x_{2}+w_{3} \ln x_{3}+w_{1} w_{2} \sum_{i=0}^{2} S_{i}\left(w_{1}-w_{2}\right)^{i} \\
& +w_{1} w_{3} \sum_{i=0}^{2} S_{i}^{\prime}\left(w_{1}-w_{3}\right)^{i}+w_{2} w_{3} \sum_{i=0}^{2} S_{i}^{\prime \prime}\left(w_{2}-w_{3}\right)^{i} \\
& +w_{1} w_{2} w_{3} \sum_{i=0}^{2} S_{i}^{\prime \prime \prime}\left(w_{1}-w_{2}-w_{3}\right)^{i}
\end{aligned}
$$

in which $S_{i}^{\text {"' }}$ are the model constants calculated using solubility data in ternary solvent mixtures.

The modified Wilson model represents a drug solubility in binary solvents at a given temperature as (61):

$$
-\ln x_{\mathrm{m}}=1-\frac{w_{1}\left(1+\ln x_{1}\right)}{w_{1}+w_{2} \lambda_{12}}-\frac{w_{2}\left(1+\ln x_{2}\right)}{w_{1} \lambda_{21}+w_{2}}
$$

in which $\lambda_{12}$ and $\lambda_{21}$ are the model parameters computed using a non-linear least square analysis.

Most of these models could be converted to a general single model (GSM) or unified cosolvency model (UCM) as has been shown in previous papers $(24,62)$. The GSM was derived from the excess free energy and the CNIBS/R-K models (24) and was already used as an empirical equation to correlate solute solubility in the pharmaceutical literature $(17,63,64)$. GSM is expressed as (24):

$$
\ln x_{m}=K_{0}+K_{1} f_{1}+K_{2} f_{1}^{2}+K_{3} f_{1}^{3}+\Lambda
$$

where $K_{0}-K_{3}$ denote the model constants calculated using least squares analysis.

Using similar algebraic manipulations and some simplifications, UCM could be derived from nonlinear cosolvency models (61) as:

$$
\ln x_{m}=\frac{K_{0}^{\prime}+K_{1}^{\prime} w_{1}+K_{2}^{\prime} w_{1}^{2}+K_{3}^{\prime} w_{1}^{3}+\Lambda}{K_{0}^{\prime \prime}+K_{1}^{\prime \prime} w_{1}+K_{2}^{\prime \prime} w_{1}^{2}+K_{3}^{\prime \prime} w_{1}^{3}+\Lambda}
$$

where $K_{i}^{\prime}$ and $K_{i}^{\prime \prime}$ terms denote the model constants.

The cosolvency models usually overestimate or underestimate the solubility data and to provide better calculations, mean predicted solubility (MPS) approach was proposed and it was shown that, MPS approach provides more accurate correlations and/or predictions. In this approach, the solubility data calculated using various cosolvency models were averaged (65).

\section{Empirical models}

The mixture response surface method for correlation of solubility values is written as:

$$
\ln x_{m}=\beta_{1} w_{1}^{\prime}+\beta_{2} w_{2}^{\prime}+\beta_{3}\left(\frac{1}{w_{1}^{\prime}}\right)+\beta_{4}\left(\frac{1}{w_{2}^{\prime}}\right)+\beta_{5} w_{1}^{\prime} w_{2}^{\prime}
$$

here, $\beta_{1}-\beta_{5}$ are model's constants and $w_{1}^{\prime}$ and $w_{2}^{\prime}$ are given by $w_{1}^{\prime}=0.96 w_{1}+0.02$ and $w_{2}^{\prime}=0.96 w_{2}+0.02$ (66).

The double log-log model for linearizing the solubility data can be presented as (67):

$$
\ln \left(\ln \frac{x_{m}}{x_{2}}\right)=\ln \left(\ln \frac{x_{m_{0.5}}}{x_{2}}\right)+D \ln \left(\frac{w_{1}}{w_{2}}\right)
$$

for $0<w_{1} \leq 0.5$

$$
\ln \left(\ln \frac{x_{1}}{x_{m}}\right)=\ln \left(\ln \frac{x_{1}}{x_{m_{0.5}}}\right)+d \ln \left(\frac{w_{2}}{0.5}\right)
$$

for $0<w_{2} \leq 0.5$ 
in which $x_{m_{0.5}}$ is drug solubility in the fraction of 0.5 of the cosolvent, $D$ and $d$ are the model's constants. The double log-log model considers whole composition range of a binary solvent mixture as solvent 1 rich area and solvent 2 rich area and believed that should provide more accurate calculations. A number of other empirical models were reported which did not attract more attention from the research groups (68).

The main disadvantage of these models (Eqs. 6-21) is that they could be used at isothermal condition and should be trained for each temperature of interest.

\section{COSOLVENCY MODELS AT VARIOUS TEMPERATURES}

\section{Semi-theoretical models}

The logarithm of the mole fraction solubility of a solute at temperature $T$ and different solvent compositions $\left(\ln x_{\mathrm{m}, \mathrm{T}}\right)$ is calculated using an extended version of the algebraic mixing rule as $(69,70)$ :

$$
\ln x_{\mathrm{m}, \mathrm{T}}=w_{1}\left(A_{1}+\frac{B_{1}}{T}\right)+w_{2}\left(A_{2}+\frac{B_{2}}{T}\right)
$$

which is just a simple replacement of $\ln x_{1, \mathrm{~T}}$ and $\ln x_{2, \mathrm{~T}}$ with their values from van't Hoff equation. It is obvious that Eq. 22 represents the ideal mixing behaviour of the solution and is not the case for most of pharmaceutical solutions. In the Jouyban-Acree model, additional solutesolvent and solvent-solvent interaction terms could cover non-ideal mixing behaviour of the solutions. It correlates the solubility data in terms of temperature and solvent composition and represented as $(71,72)$ :

$$
\begin{aligned}
\ln x_{\mathrm{m}, \mathrm{T}}= & w_{1} \ln x_{1, \mathrm{~T}}+w_{2} \ln x_{2, \mathrm{~T}} \\
& +\frac{w_{1} w_{2}}{T} \sum_{i=0}^{2} J_{\mathrm{i}}\left(w_{1}-w_{2}\right)^{\mathrm{i}}
\end{aligned}
$$

where $x_{1, \mathrm{~T}}$ and $x_{2, \mathrm{~T}}$ are the solubility in the mono-solvents 1 and 2 at various temperatures $\mathrm{T}$ and $J_{i}$ are the model constants computed using regression of $\left(\ln x_{\mathrm{m}, \mathrm{T}}-w_{1} \ln x_{1, \mathrm{~T}}-w_{2} \ln x_{2, \mathrm{~T}}\right)$ against $\frac{w_{1} w_{2}}{T} \quad, \quad \frac{w_{1} w_{2}\left(w_{1}-w_{2}\right)}{T}$ and $\frac{w_{1} w_{2}\left(w_{1}-w_{2}\right)^{2}}{T}(57,72)$. Equation 23 requires two experimental solubility data points at each temperature and this restricts its practical applications. On the other hand, since the effect of drug solid state charactristics is an important parameter in its solubility, e.g. different polymorphs of a drug, and its effects could be reflected in $x_{1, \mathrm{~T}}$ and $x_{2, \mathrm{~T}}$ values. Employing these experimental data points in such cases is preferred and provided a useful tool for predictive purposes. As an example, the solubility of two polymorphs of a drug could be represented using the model parameters of one polymorph and the solubility data of other polymorph in the monosolvents (73).

To provide a more practical version of the model to calculate drug solubility in solvent mixtures, the Jouyban-Acree model could be combined with van't Hoff equation as $(69,74$, 75):

$$
\begin{aligned}
\ln x_{\mathrm{m}, \mathrm{T}}= & w_{1}\left(A_{1}+\frac{B_{1}}{T}\right)+w_{2}\left(A_{2}+\frac{B_{2}}{T}\right) \\
& +\frac{w_{1} w_{2}}{T} \sum_{i=0}^{2} J_{\mathrm{i}}\left(w_{1}-w_{2}\right)^{\mathrm{i}}
\end{aligned}
$$

where $A_{\mathrm{i}}, B_{\mathrm{i}}$ and $J_{\mathrm{i}}$ parameters have the same meanings in Eqs. 1 and 23. The constants of Eq. 24 could be computed using either:

1) regression of $\ln x_{1, \mathrm{~T}}$ against $\frac{1}{T}, \ln x_{2, \mathrm{~T}}$ against $\frac{1}{T}$ (to obtain A and B terms of van't Hoff equation), then regression of $\left(\ln x_{\mathrm{m}, \mathrm{T}}-w_{1}\left(A_{1}+\frac{B_{1}}{T}\right)-w_{2}\left(A_{2}+\frac{B_{2}}{T}\right)\right)$ against $\frac{w_{1} w_{2}}{T}, \frac{w_{1} w_{2}\left(w_{1}-w_{2}\right)}{T}$ and $\frac{w_{1} w_{2}\left(w_{1}-w_{2}\right)^{2}}{T}$; which is a recommended procedure, or:

2) regression of $\ln x_{m, \mathrm{~T}}$ against $w_{1}, \frac{w_{1}}{T}$, $w_{2}, \frac{w_{2}}{T}, \frac{w_{1} w_{2}}{T}, \frac{w_{1} w_{2}\left(w_{1}-w_{2}\right)}{T}$ and $\frac{w_{1} w_{2}\left(w_{1}-w_{2}\right)^{2}}{T}$ using a no intercept least square analysis; which is a recommended 
procedure for data sets in which the solubility in neat mono-solvents are not available.

The numerical values of $J$ terms computed from two numerical methods are slightly different from each other, but the overall fitness of the models is the same.

The model was also combined with Apelblat model as (76):

$$
\begin{aligned}
\ln x_{\mathrm{m}, \mathrm{T}}= & w_{1}\left(A_{1}^{\prime \prime}+\frac{B_{1}^{\prime \prime}}{T}+C_{1}^{\prime \prime} \ln T\right)+w_{2}\left(A_{2}^{\prime \prime}+\frac{B_{2}^{\prime \prime}}{T}+C_{2}^{\prime \prime} \ln T\right) \\
& +\frac{w_{1} w_{2}}{T} \sum_{i=0}^{2} J_{\mathrm{i}}\left(w_{1}-w_{2}\right)^{\mathrm{i}}
\end{aligned}
$$

in which $A_{1}^{\prime \prime}, B_{1}^{\prime \prime}, C_{1}^{\prime \prime}, A_{2}^{\prime \prime}, B_{2}^{\prime \prime}$, and $C_{2}^{\prime \prime}$ are the model constants.

\section{Empirical models}

Equation 22 could be re-arranged as:

$$
\begin{aligned}
& \ln x_{\mathrm{m}, \mathrm{T}}=w_{1}\left(A_{1}+\frac{B_{1}}{T}\right)+\left(1-w_{1}\right)\left(A_{2}+\frac{B_{2}}{T}\right) \\
& \ln x_{\mathrm{m}, \mathrm{T}}=A_{1} w_{1}+\frac{B_{1} w_{1}}{T}+A_{2}+\frac{B_{2}}{T}-A_{2} w_{1}-\frac{B_{2} w_{1}}{T}
\end{aligned}
$$

$$
\begin{aligned}
& \ln x_{\mathrm{m}, \mathrm{T}}=A_{2}+\frac{B_{2}}{T}+\left(A_{1}-A_{2}\right) w_{1}+\frac{\left(B_{1}-B_{2}\right) w_{1}}{T} \\
& \ln x_{\mathrm{m}, \mathrm{T}}=E_{0}+\frac{E_{1}}{T}+E_{2} w_{1}+\frac{E_{3} w_{1}}{T}
\end{aligned}
$$

in which $E_{0}-E_{3}$ are the model constants.

Yang et al. (77) and Sun et al. (78) manipulated Eq. 23 and reported a modified version of the model as:

$$
T \ln x_{m}=G_{0}+G_{1} T+G_{2} T x_{2}+G_{3} T x_{2}+G_{4} x_{2}^{2}+G_{5} x_{2}^{3}+G_{6} x_{2}^{4}
$$

in which $G$ terms are the model constants. There is no way to derive Eq. 30 from their manipulations and the correct derivation could be obtained from a similar manipulations on Eq. 24 as has been shown in previous papers $(79,80)$. The correct derivation is:

The replacement of $w_{2}$ with $\left(1-w_{1}\right)$ in Eq. 24 and series of algebraic manipulations:

$T \ln x_{m, T}=\left(B_{2}-B_{2} w_{1}+B_{1} w_{1}\right) T+\left(A_{1} w_{1}+A_{2}-A_{2} w_{1}\right)$
$+\left[J_{0} w_{1}-J_{0} w_{1}^{2}\right]+\left[\left(J_{1} w_{1}-J_{1} w_{1}^{2}\right)\left(2 w_{1}-1\right)\right]+\left[\left(J_{2} w_{1}-J_{2} w_{1}^{2}\right)\left(4 w_{1}^{2}-4 w_{1}+1\right)\right]$

$T \ln x_{m, T}=B_{2} T-B_{2} w_{1} T+B_{1} w_{1} T+A_{1} w_{1}+A_{2}-A_{2} w_{1}$

$+\left[J_{0} w_{1}-J_{0} w_{1}^{2}\right]+\left[2 J_{1} w_{1}^{2}-J_{1} w_{1}-2 J_{1} w_{1}^{3}+J_{1} w_{1}^{2}\right]$

$+\left[4 J_{2} w_{1}^{3}-4 J_{2} w_{1}^{2}+J_{2} w_{1}-4 J_{2} w_{1}^{4}+4 J_{2} w_{1}^{3}-J_{2} w_{1}^{2}\right]$

and like terms are combined:

$$
\begin{aligned}
& T \ln x_{m, T}=A_{2}+\left(A_{1}-A_{2}+J_{0}-J_{1}+J_{2}\right) w_{1}+B_{2} T+\left(B_{1}-B_{2}\right) w_{1} T \\
& +\left(-J_{0}+3 J_{1}-5 J_{2}\right) w_{1}^{2}+\left(-2 J_{1}+8 J_{2}\right) w_{1}^{3}+\left(-4 J_{2}\right) w_{1}^{4}
\end{aligned}
$$

Since all of the A, B and $\mathbf{J}$ terms in Eq. 36 are constant values, one may re-write it in a simplified version of Eq. 30.

Equation 24 could be re-arranged as:

$$
\ln x_{\mathrm{m}, \mathrm{T}}=G_{1}+\frac{G_{2}}{T}+G_{3} w_{1}+\frac{G_{4} w_{1}}{T}+\frac{G_{5} w_{1}^{2}}{T}+\frac{G_{6} w_{1}^{3}}{T}+\frac{G_{7} w_{1}^{4}}{T}
$$

by replacing $w_{2}$ with $\left(1-w_{1}\right)$ and further algebraic manipulations $(81,82) . G$ terms are the model constants and computed using a classical least square analysis. 
The correlation abilities of Eqs. 24, 30 and 37 were compared employing 56 solubility data sets of drugs in aqueous and non-aqueous binary solvent mixtures at various temperatures (83). The obtained mean percentage deviations (MPD) were $9.9 \pm 11.8,14.1 \pm 21.4 \%$ and $14.1 \pm 21.4 \%$, respectively for Eqs. 24, 30 and 37 . There were five data sets producing relatively large MPD values for all models, and by excluding these five data sets, the MPDs were reduced to $6.6 \pm 4.5,8.6$ $\pm 6.6 \%$ and $8.7 \pm 6.6 \%$, respectively for the mentioned equations (83).

Zhou et al. (84) introduced a modified version of Eq. 25 by replacing $w_{2}$ with $\left(1-w_{1}\right)$. The modified Jouyban-Acree-Apelblat model (85) is:

$$
\ln x_{\mathrm{m}, \mathrm{T}}=F_{1}+\frac{F_{2}}{T}+F_{3} \ln T+F_{4} w_{1}+\frac{F_{5} w_{1}}{T}+\frac{F_{6} w_{1}^{2}}{T}+\frac{F_{7} w_{1}^{3}}{T}+\frac{F_{8} w_{1}^{4}}{T}+F_{9} w_{1} \ln T
$$

in which $F$ terms are the model constants.

Although both modified versions and the classical version of the Jouyban-Acree model produce the same accuracies for correlation of the solubility data of a given drug in a certain cosolvent + water mixtures, the classical version of the Jouyban-Acree model is preferred for future works. The main reasons for this preference are:

1. Theoretical basis of the model $(71,72)$

2. Capability of providing the most accurate correlation/prediction for solubility of drugs in various cosolvent + water mixtures $(63,83$, 86)

3. Possibility of extension of the model's applicability to calculate the solubility in ternary or higher order solvent mixtures (8789)

4. Providing generally trained models to predict the solubility of drugs in a given cosolvent + water mixtures (90-96)

5. Providing generally trained model for a given drug in different solvent mixtures $(97,98)$

6. Accurate representation of some commonly observed phenomena in the solutions such as chameleonic effect (99) and solubility of various polymorphs of a drug in cosolvent + water mixtures (73)

7. Providing globally trained versions of the model using Abraham parameters (100) and/or Hansen solubility parameters (101)

8. The model could be used for representing both solvent composition effects and salt formation $(102,103)$, surfactants $(104,105)$, complexing agents (106-108), combined effects of surfactants and complexing agents (109), polymers $(110,111)$, and ionic strength (112).

9. Possibility of representing drug's $\mathrm{pKa}$ in solvent mixtures at various temperatures (27)

10. Representing thermodynamic parameters of the solutions in mixed solvents (113)
11. Possibility of representing the solvent mixtures properties such as viscosity (31), density (32) etc at various temperatures. The general form of the Jouyban-Acree model is:

$$
\ln P C P_{m, T}=w_{1} \ln P C P_{1, T}+w_{2} \ln P C P_{2, T}+w_{1} w_{2} \sum_{i=0}^{2} \frac{J_{i}\left(w_{1}-w_{2}\right)^{i}}{T}
$$

where $P C P_{m, T}, P C P_{1, T}$ and $P C P_{2, T}$ are the numerical values of the physico-chemical property of the mixture and solvents 1 and 2 at temperature $T$, respectively, $w_{1}$ and $w_{2}$ are the volume (weight or mole) fractions of solvents 1 and 2 in the mixture and $J_{i}$ represent the model constants.

12. The applicability of the model to extend for representation of the solubility and $P C P S$ in ternary solvents as:

$$
\begin{aligned}
\ln P C P_{m, T} & =w_{1} \ln P C P_{1, T}+w_{2} \ln P C P_{2, T}+w_{3} \ln P C P_{3, T} \\
& +w_{1} w_{2} \sum_{i=0}^{2} \frac{J_{i}\left(w_{1}-w_{2}\right)^{i}}{T}+w_{1} w_{3} \sum_{i=0}^{2} \frac{J_{i}^{\prime}\left(w_{1}-w_{3}\right)^{i}}{T} \\
& +w_{2} w_{3} \sum_{i=0}^{2} \frac{J_{i}^{\prime \prime}\left(w_{2}-w_{3}\right)^{i}}{T}+w_{1} w_{2} w_{3} \sum_{i=0}^{2} \frac{J_{i}^{\prime \prime}\left(w_{1}-w_{2}-w_{3}\right)^{i}}{T}
\end{aligned}
$$

where subscript 3 is the solvent 3 characteristics, $J_{i}^{\prime}, J_{i}^{\prime \prime}$ and $J_{i}^{\prime \prime}$ are the sub-binary model constants (114).

\section{ACCURACY OF COSOLVENCY MODELS}

MPD is one of the most commonly used scaleindependent accuracy criteria in cosolvency computations. The possible determination errors in solubility experiments may result in an outlier point which will produce large MPD value in the computations. The MPD value could be directly compared with the relative standard deviation which is a measure of accuracy and precision of experimental determination procedure. It could be extremely large when the target experimental 
solubility datum is very close to zero (83). MPD will be $\sim 100$ when the calculated solubility datum is very close to zero. On the other hand, scaledependent accuracy measures such as average absolute error (AAE) and root mean square error (RMSE) are vastly affected from the high solubility data and neglects the lower ones. The solubility in mole fraction unit is ranged from $\sim 0$ to $\sim 1$. This is the reason why MPD was the most widely used criteria despite its mentioned limitation.

The other generally used accuracy criterion includes the RMSE defined as (115-116):

$$
R M S E=\sqrt{\frac{\sum(\text { Observed }-\operatorname{Pr} \text { edicted })^{2}}{N}}
$$

where $N$ is the number of predicted solubility data points. The next criterion is the AAE which is defined as $(115,117)$ :

$$
A A E=\frac{\sum \mid \text { Observed }- \text { Pr edicted } \mid}{N}
$$

The RMSE and AAE values could be defined in $\operatorname{logarithmic}\left(\log x_{m}\right.$ or $\left.\ln x_{m}\right)$ or arithmatic $\left(x_{m}\right)$ scales and to compare its reported values in different papers, the scale should be kept in mind. The percentage deviation (\%Dev.) (118-122) is:

$$
\% \text { Dev. }=\left(\frac{100}{N}\right) \sum\left|\ln \left(\frac{\text { Pr edicted }}{\text { Observed }}\right)\right|
$$

The mean squared deviation (MSD) was also used in the literature:

$$
M S D=\sqrt{\frac{\left(x_{m}^{\text {Calculated }}-x_{m}^{\text {Observed }}\right)^{2}}{N-1-p}}
$$

where $p$ is the number of the parameters of the model (123).

The MPD was used by our group $(61,83$, 91-95) and is defined as:

$$
M P D=\frac{100}{N} \sum_{1}^{N}\left(\frac{\left|x_{m}^{\text {Calculated }}-x_{m}^{\text {Observed }}\right|}{x_{m}^{\text {Observed }}}\right)
$$

The same definition was also used in some reports using various terminologies, such as percent mean error (124), average percentage deviation (125) and percent deviation (63).

The squares of the percent difference between calculated and experimental solubilities $\left(\sum(\% D)^{2}\right)$ is defined as $(126)$ :

$$
\sum(\% D)^{2}=\sum_{i=1}^{N}\left\{100\left[\frac{x_{m}^{\text {Calculated }}-x_{m}^{\text {Observed }}}{x_{m}^{\text {Observed }}}\right]\right\}^{2}
$$

\section{Accuracy of correlative models}

The ideal value for the accuracy criterion for a correlative model is $\sim 0$ which means data excellently fit to the model. However, due to the experimental and other erros associated with the experimental data, the value is usually more than zero $(63,71,83,86)$. One may consider the accuracy criterion around the uncertainity values for repeated experiments (which is usually 1$10 \%$ ) as an ideal value for the accuracy of the correlative models. As discussed in this work, MPD is a very similar term to the relative standard deviation (RSD) for repeated experiments and the expected MPD for correlative models could be considered in the range of 1 to $10 \%$ as an acceptable range.

Barzegar-Jalali et al. (126) compared the accuracy of 3 cosolvency models for correlating the solubility data sets of 11 drugs in pharmaceutical cosolvents + water at $25{ }^{\circ} \mathrm{C}$ using $\sum(\% D)^{2}$ as an accuracy criterion and found that the CNIBS/R-K model provided the most accurate correlations.

\section{Accuracy of predictive models trained using a} minimum number of experimental data points

Solubility prediction by employing the trained models using a minimum number of experimental data points $(65,69,126-132)$ is perhaps the most accurate and feasible prediction method so far. It has been shown that the trained models using sufficient number of training data points provide acceptable predictions and could be used in the pharmaceutical industry. One could predict the solubility of a drug at a narrow temperature range after training the van't Hoff equation using just two experimental data points, since the van't Hoff equation is a linear model (69). For solubility prediction of a drug in a binary solvent mixture, one datum $(10,14,90)$, two data points $(10,129)$, three data points (128), four data ponits (128), five data points $(65,126)$ and seven data points $(107,131)$ have been examined. The overall MPD 
for predictive models is $10-80 \%$ for various models used in recent publications. As a general rule, the more data points in the training set, resulted in more accurate solubility predictions. On the other hand, more independent variables included, the more comprehensive solubility predictions were provided, however less accurate predictions were made. As an example, the van't Hoff model with only one independent variable, i.e. temperature, produced the most accurate predictions, while the Jouyban-Acree-Abraham model (100) with four independent variables, i.e. solvent composition, temperature, nature of solvents and nature of solutes, produced less accurate predictions. This point should be considered when accuracy comparison of the solubility models are investigated.

\section{Models for a given drug in various solvent mixtures}

Trained versions of the Jouyban-Acree model were reported for prediction of paracetamol (87) and salicylic acid (132) in water + ethanol + propylene glycol ternary and sub-binary solvent mixtures. A trained version of the Jouyban-AcreeAbraham model was proposed to calculate the solubility of hesperidin in a number of cosolvents + water mixtures at various temperatures as (133):

$$
\begin{aligned}
& \ln x_{m, T}=w_{1} \ln x_{1, T}+w_{2} \ln x_{2, T} \\
& +\left(\frac{w_{1} w_{2}}{T}\right)\left\{-38893.1 c_{1}^{2}+9164.4 e_{1}^{2}-5860.6 a_{1}^{2}+158.0 b_{1}^{2}\right\} \\
& +\left(\frac{w_{1} w_{2}\left(w_{1}-w_{2}\right)}{T}\right)\left\{111935.7 c_{1}^{2}-14412.0 e_{1}^{2}+14625.7 a_{1}^{2}-267.1 b_{1}^{2}\right\} \\
& +\left(\frac{w_{1} w_{2}\left(w_{1}-w_{2}\right)^{2}}{T}\right)\left\{-92240.1 c_{1}^{2}-7131.4 e_{1}^{2}-8364.4 a_{1}^{2}+210.1 b_{1}^{2}\right\}
\end{aligned}
$$

which is a simplified version of Eq. 54. Abraham solvent coefficients; $e$ is the excess molar refraction, $s$ is the dipolarity/polarizability of the solvent, $a$ denotes the hydrogen-bond acidity of solvent, $b$ stands for hydrogen-bond basicity of solvent, and $v$ is the McGowan volume of the solvent. Another trained version was reported for calculating the solubility of lamotrigine in nonaqueous binary solvent mixtures as (134):

$$
\begin{aligned}
& \ln x_{m, T}=w_{1} \ln x_{1, T}+w_{2} \ln x_{2, T} \\
& +\left(\frac{w_{1} w_{2}}{T}\right)\left\{\begin{array}{l}
238.81+5221.44\left[\left(c_{1}-c_{2}\right)^{2}\right]-10525.96\left(e_{1}-e_{2}\right)^{2} \\
+141.65\left(s_{1}-s_{2}\right)^{2}+368.67\left(a_{1}-a_{2}\right)^{2}-86.57\left(b_{1}-b_{2}\right)^{2} \\
+251.30\left(v_{1}-v_{2}\right)^{2}
\end{array}\right\} \\
& +\left(\frac{w_{1} w_{2}\left(w_{1}-w_{2}\right)}{T}\right)\left\{\begin{array}{l}
-191.11+30503.53\left[\left(c_{1}-c_{2}\right)^{2}\right]+94447.51\left(e_{1}-e_{2}\right)^{2} \\
-1446.39\left(s_{1}-s_{2}\right)^{2}-954.07\left(a_{1}-a_{2}\right)^{2}+465.31\left(b_{1}-b_{2}\right)^{2}
\end{array}\right\} \\
& +\left(\frac{w_{1} w_{2}\left(w_{1}-w_{2}\right)^{2}}{T}\right)\left\{\begin{array}{l}
303.74-197.26\left(s_{1}-s_{2}\right)^{2} \\
+111.22\left(b_{1}-b_{2}\right)^{2}-1831.16\left(v_{1}-v_{2}\right)^{2}
\end{array}\right\}
\end{aligned}
$$

\section{Models for various drugs in a given solvent} mixture

The predictive version of the log-linear model of Yalkowsky (135) was applied to predict the solubility of drugs in various cosolvent + water mixtures at room temperature using:

$$
\ln x_{\mathrm{m}}=\ln x_{2}+w_{1}\left(M \log _{10} P+N\right)
$$

where $\log _{10} P$ is the logarithm of drug's partition coefficient. Table 1 summerized the $\mathrm{M}$ and $\mathrm{N}$ values for a number of cosolvent systems. 
Table 1. Numerical values of $\mathrm{M}$ and $\mathrm{N}$ values of common cosolvents for calculating the slope $(\sigma)$ of the log-linear model (133)

\begin{tabular}{lcc}
\hline & $\mathrm{M}$ & $\mathrm{N}$ \\
\hline Acetone & 1.14 & -0.10 \\
Acetonitrile & 1.16 & -0.49 \\
Butylamine & 0.64 & 1.86 \\
Dimethyl acetamide & 0.96 & 0.75 \\
Dimethyl formamide & 0.83 & 0.92 \\
Dimethyl sulphoxide & 0.79 & 0.95 \\
Dioxane & 1.08 & 0.40 \\
Ethanol & 0.95 & 0.30 \\
Ethylene glycol & 0.68 & 0.37 \\
Glycerol & 0.35 & 0.28 \\
Methanol & 0.89 & 0.36 \\
Polyethylene glycol 400 & 0.88 & 0.68 \\
1-Propanol & 1.09 & 0.01 \\
2-Propanol & 1.11 & -0.50 \\
Propylene glycol & 0.78 & 0.37 \\
Carbitol & $1.60^{\mathrm{a}}$ & $5.43^{\mathrm{a}}$ \\
\hline a Taken from a reference (94). & & \\
\hline
\end{tabular}

Attempts were made to calculate the solubility of structurally related drugs in a given cosolvent + water mixtures to provide prediction tools for practical applications in the pharmaceutical industry. Bustamante et al. (19) proposed a modified version of the extended Hildebrand solubility approach as:

$$
\ln x_{\mathrm{m}}=B_{0}+B_{1} \ln x_{1}+B_{2} \ln x_{2}+B_{3} \delta_{m} \delta_{\text {Drug }}+B_{4} \delta_{m}^{2}+B_{5} \delta_{m}^{3}+B_{6} \delta_{m b}
$$

in which $\delta_{m}$ is the solubility parameter of the solvent mixture calculated using $\left(w_{1} \delta_{1}+w_{2} \delta_{2}\right)$, and $\delta_{m b}$ is the basic solubility parameter of the solvent mixture. The accuracy of Eq. 56 was compared with that of the CNIBS/R-K model using 8 solubility data sets of sulfonamides in dioxane + water and 8 alkylbenzoates in propylene glycol + water mixtures, where the CNIBS/R-K model provided more accurate correlations (125).

Abraham and Acree (14) proposed the Abraham solvent coefficients for ethanol + water mixtures with 0.1 fraction intervals and predicted the solubility of various drugs in ethanol + water mixtures employing their Abraham solute parameters (14). The accuracy of this method was not compared using accuracy criterions and the authors just compared using graphical comparisons of a sample data sets (see Figures 14 of the original paper (14) for details). The graphical comparisons reveal that the accuracy of the proposed method (14) was comparable with that of the Jouyban-Acree-Abraham model (Eq. 65) for calculating the solubility of drugs in ethanol + water mixtures. A disadvantage of the method is that it cannot be used for interpolation of the solubility data in the fractions other than 0.1 intervals.

The trained versions of Eq. 23 were reported for solubility prediction of drugs in the aqueous mixtures of ethanol and several cosolvents at various temperatures (90-96). In these models, the $J$ terms of Eq. 23 were assumed as independent parameters from drugs interactions which is not the case for most of the pharmaceutical systems. Attempts were made to cover this point by

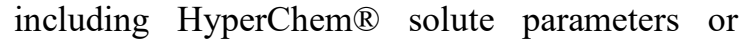
Abraham solvent and solute parameters in the computations. The calculated structural parameters of drugs using HyperChem 7.0 (136) were employed to consider the effects of drugs' stuructures on their solubilities, and the obtained models for dioxane + water and ethyl acetate + ethanol solvent mixtures were: 


$$
\begin{aligned}
\ln x_{m, T}= & {\left[w_{1} \ln x_{1, T}+w_{2} \ln x_{2, T}+w_{1} w_{2}\left(\frac{2206.9}{T}+\frac{1173.1\left(w_{1}-w_{2}\right)}{T}+\frac{1997.4\left(w_{1}-w_{2}\right)^{2}}{T}\right)\right] } \\
& +3.113 \mathrm{HE}^{\prime}-5.124 \mathrm{HOMO}^{\prime}-9.697 T E^{\prime} \\
& +11.782 \mathrm{Vol}^{\prime}+0.238 \log P^{\prime} \\
\ln x_{m, T}= & {\left[w_{1} \ln x_{1, T}+w_{2} \ln x_{2, T}+w_{1} w_{2}\left(\frac{881.9}{T}+\frac{289.4\left(w_{1}-w_{2}\right)}{T}+\frac{494.1\left(w_{1}-w_{2}\right)^{2}}{T}\right)\right] } \\
& +1.020 \mathrm{HE}^{\prime}-2.818 \mathrm{HOMO}^{\prime}-1.143 T E^{\prime} \\
& +3.068 \mathrm{Vol}^{\prime}-0.072 \log P^{\prime}
\end{aligned}
$$

where $H E$ is hydration energy, HOMO is energy of the highest occupied molecular orbital, TE is total energy, $\mathrm{Vol}$ is molar volume, and $\log P$ is the logarithm of partition coefficient, all computed by HyperChem as described in the published work (136). Their normalized values were used in the computations and calculated using:

$$
H C^{\prime}=\frac{w_{1} w_{2} H C}{\overline{H C}}
$$

where $\overline{H C}$ is the mean of $H C$ value for the investigated drugs. Eqs. 57 and 58 were correlated the data with the overall MPDs of $17.9 \%$ and $9.6 \%$, respectively for dioxane + water and ethyl acetate + ethanol solvent mixtures which were significantly less than their simplified models without structural parameters (136). More variables from HyperChem computations were included to the model and the results were tested using solubility data sets in aquoeus binary mixtures of propylene glycol, ethanol and PEG 400. The combined model was:

$$
\begin{aligned}
& \ln x_{m, T}=\left[w_{1} \ln x_{1, T}+w_{2} \ln x_{2, T}+w_{1} w_{2}\left(\frac{J_{0}}{T}+\frac{J_{1}\left(w_{1}-w_{2}\right)}{T}+\frac{J_{2}\left(w_{1}-w_{2}\right)^{2}}{T}\right)\right] \\
& +J_{3} S A A^{\prime}+J_{4} H E^{\prime}+J_{5} \log P^{\prime}+J_{6} M R^{\prime}+J_{7} M W^{\prime}+J_{8} T E^{\prime}+J_{9} D M^{\prime}+J_{10} H O M O^{\prime}+J_{11} L U M O^{\prime}+J_{12} V_{O} l^{\prime}
\end{aligned}
$$

The Abraham solute parameters, i.e. $E, S, \mathrm{~A}, B$ and $V$ represent the interactions of solute with solvent system. The combined version of Eq. 23 with Abraham parameters was (100):

$$
\begin{aligned}
\ln x_{\mathrm{m}, \mathrm{T}} & =w_{1} \ln x_{1, \mathrm{~T}}+w_{2} \ln x_{2, \mathrm{~T}}+ \\
& \frac{w_{1} w_{2}}{T}\left\{\left(\kappa_{0}+\kappa_{1} E+\kappa_{2} S+\kappa_{3} A+\kappa_{4} B+\kappa_{5} V\right\}\right. \\
& \frac{w_{1} w_{2}\left(w_{1}-w_{2}\right)}{T}\left\{\left(\kappa_{0}^{\prime}+\kappa_{1}^{\prime} E+\kappa_{2}^{\prime} S+\kappa_{3}^{\prime} A+\kappa_{4}^{\prime} B+\kappa_{5}^{\prime} V\right\}\right. \\
& \frac{w_{1} w_{2}\left(w_{1}-w_{2}\right)^{2}}{T}\left\{\left(\kappa_{0}^{\prime \prime}+\kappa_{1}^{\prime \prime} E+\kappa_{2}^{\prime \prime} S+\kappa_{3}^{\prime \prime} A+\kappa_{4}^{\prime \prime} B+\kappa_{5}^{\prime \prime} V\right\}\right.
\end{aligned}
$$

in which $\kappa$ terms are the model constants. Trained versions of Eq. 61 were provided for dioxane + water (100), ethanol + water (100), ethanol + ethyl acetate (138), ethanol + propylene glycol (139) and some other binary solvent mixtures. 
Models for calculating the solubility of various drugs in different binary solvent mixtures:

An attempt was also made to provide a general version of the Jouyban-Acree-Abraham model to correlate the solubility of anthracene in non-aqueous binary solvents as:

$$
\begin{aligned}
& \ln x_{m}=w_{1} \ln x_{1}+w_{2} \ln x_{2} \\
& +w_{1} w_{2}\left[0.128-4.772\left(c_{1}-c_{2}\right)^{2}-1.123\left(e_{1}-e_{2}\right)^{2}+0.546\left(s_{1}-s_{2}\right)^{2}+0.670\left(b_{1}-b_{2}\right)^{2}+1.262\left(v_{1}-v_{2}\right)\right] \\
& +w_{1} w_{2}\left(w_{1}-w_{2}\right)\left[0.194-10.404\left(c_{1}-c_{2}\right)^{2}-1.746\left(e_{1}-e_{2}\right)^{2}+0.133\left(s_{1}-s_{2}\right)^{2}+0.372\left(b_{1}-b_{2}\right)^{2}-1.402\left(v_{1}-v_{2}\right)\right] \\
& +w_{1} w_{2}\left(w_{1}-w_{2}\right)^{2}\left[-0.047-1.340\left(c_{1}-c_{2}\right)^{2}-0.934\left(e_{1}-e_{2}\right)^{2}+0.140\left(s_{1}-s_{2}\right)^{2}+0.178\left(b_{1}-b_{2}\right)^{2}+0.876\left(v_{1}-v_{2}\right)\right]
\end{aligned}
$$

where the overall MPD of $5.5 \%$ was obtained by employing the experimental solubility data of anthracene in the mono-solvents as input data. When the solubilities of anthracene in the monosolvents predicted by the Abraham model were replaced in the above equation, the overall MPD of $37.9 \%$ was obtained (140). The applicability of Eq. 62 to predict the solubility of anthracene in 49 binary solvents and 32 ternary solvent systems have been shown where the overall MPD of $7.9 \%$ and $10.7 \%$ were obtained. By replacing the Abraham equation predicted solubilities in the mono-solvents, the overall MPDs of $47.9 \%$ and $23.9 \%$, were observed respectively for binary and ternary prediction data sets (141).

To provide more generally trained models, both solutes and solvents parameters were included in the computations. The solubility of five polycyclic aromatic hydrocarbons in nonaqueous binary solvent was correlated using:

$$
\begin{aligned}
& \ln x_{m}=w_{1} \ln x_{1}+w_{2} \ln x_{2} \\
& +w_{1} w_{2}\left[0.028+2.123\left(c_{1}-c_{2}\right)^{2}-0.160 E\left(e_{1}-e_{2}\right)^{2}+0.282 S\left(s_{1}-s_{2}\right)^{2}+1.713 B\left(b_{1}-b_{2}\right)^{2}+2.006 V\left(v_{1}-v_{2}\right)\right] \\
& +w_{1} w_{2}\left(w_{1}-w_{2}\right)\left[0.033+0.670\left(c_{1}-c_{2}\right)^{2}-0.477 E\left(e_{1}-e_{2}\right)^{2}+0.051 S\left(s_{1}-s_{2}\right)^{2}+0.476 B\left(b_{1}-b_{2}\right)^{2}-0.234 V\left(v_{1}-v_{2}\right)\right] \\
& +w_{1} w_{2}\left(w_{1}-w_{2}\right)^{2}\left[0.022+2.024\left(c_{1}-c_{2}\right)^{2}-0.204 E\left(e_{1}-e_{2}\right)^{2}+0.034 S\left(s_{1}-s_{2}\right)^{2}+0.243 B\left(b_{1}-b_{2}\right)^{2}+0.848 V\left(v_{1}-v_{2}\right)\right]
\end{aligned}
$$

which calculates the solute's solubility with the overall MPD of $4.7 \%$. This MPD value is quite reasonable, when it was compared with the relative standard deviation of the repeated experiments which is between 5 to $10 \%$. To provide an in silico version of the model, the solute's solubilty in the mono-solvents were calculated using the Abraham model and included in Eq. 63 instead of $x_{1}$ and $x_{2}$ values, where the overall MPD value of $33.4 \%$ was obtained (142). Further predictions for 80 data sets of anthracene and pyrene in non-aqueous ternary solvent mixtures confirmed the good prediction capacity of Eq. 63 (143). The solutesolvent interactions of polycyclic aromatic hydrocarbons and non-aqueous solvents are not too complex, so the obtained models are accurate for these sorts of solutions. A similar version of the model for calculating the molar solubility of drugs in binary solvent mixtures was proposed as (90):

$$
\begin{aligned}
& \ln x_{\mathrm{m}, \mathrm{T}}=w_{1} \ln x_{1, \mathrm{~T}}+w_{2} \ln x_{2, \mathrm{~T}} \\
& +2.303\left(\frac{w_{1} w_{2}}{T}\right)\left\{\begin{array}{l}
\left(2113.119-1093.783\left[\left(c_{1}-c_{2}\right)^{2}\right]+3380.661\left[\left(E\left(e_{1}-e_{2}\right)^{2}\right]-13.865\left[\left(S\left(s_{1}-s_{2}\right)^{2}\right]\right.\right.\right. \\
-4.921\left[\left(A\left(a_{1}-a_{2}\right)^{2}\right]-5.659\left[\left(B\left(b_{1}-b_{2}\right)^{2}\right]+15.250\left[\left(V\left(v_{1}-v_{2}\right)^{2}\right]\right.\right.\right.
\end{array}\right\} \\
& +2.303\left(\frac{w_{1} w_{2}}{T}\right)\left(w_{1}-w_{2}\right)\left\{\begin{array}{l}
-2001.561+1142.780\left[\left(c_{1}-c_{2}\right)^{2}\right]-2735.160\left[\left(E\left(e_{1}-e_{2}\right)^{2}\right]-38.541\left[\left(S\left(s_{1}-s_{2}\right)^{2}\right]\right.\right. \\
+13.176\left[\left(A\left(a_{1}-a_{2}\right)^{2}\right]+0.811\left[\left(B\left(b_{1}-b_{2}\right)^{2}\right]+38.508\left[\left(V\left(v_{1}-v_{2}\right)^{2}\right]\right.\right.\right.
\end{array}\right\} \\
& +2.303\left(\frac{w_{1} w_{2}}{T}\right)\left(w_{1}-w_{2}\right)^{2}\left\{\begin{array}{l}
1474.963-1507.479\left[\left(c_{1}-c_{2}\right)^{2}\right]+4421.302\left[E\left(e_{1}-e_{2}\right)^{2}\right]+17.981\left[S\left(s_{1}-s_{2}\right)^{2}\right] \\
-21.196\left[A\left(a_{1}-a_{2}\right)^{2}\right]+6.595\left[B\left(b_{1}-b_{2}\right)^{2}\right]-13.386\left[V\left(v_{1}-v_{2}\right)^{2}\right]
\end{array}\right\}
\end{aligned}
$$

in which $e_{1}, b_{1}, s_{1}, a_{1}, b_{1}, v_{1}$ and $e_{2}, b_{2}, s_{2}, a_{2}, b_{2}, v_{2}$ are the Abraham solvation parameters of solvents
1 and 2 and $w_{1}$ and $w_{2}$ are the mass fractions of solvents 1 and 2 in binary mixtures, respectively. 
The model correlates the solubility of drugs in four aqueous-cosolvent mixtures with the overal MPD of $18.5 \%$. Theoretically the model should be able to predict the solubility of solutes employing the solubilities in the mono-solvents. An updated version of the model for drugs solubility prediction in the binary solvents at various temperatures was proposed as (100):

$$
\begin{aligned}
& \ln x_{\mathrm{m}, \mathrm{T}}=w_{1} \ln x_{1, \mathrm{~T}}+w_{2} \ln x_{2, \mathrm{~T}} \\
& +2.303\left(\frac{w_{1} w_{2}}{T}\right)\left\{\begin{array}{l}
\left(1639.07-561.01\left[\left(c_{1}-c_{2}\right)^{2}\right]-1344.81\left[\left(E\left(e_{1}-e_{2}\right)^{2}\right]-18.22\left[\left(S\left(s_{1}-s_{2}\right)^{2}\right]\right.\right.\right. \\
-3.65\left[\left(A\left(a_{1}-a_{2}\right)^{2}\right]+0.86\left[\left(B\left(b_{1}-b_{2}\right)^{2}\right]+4.40\left[\left(V\left(v_{1}-v_{2}\right)^{2}\right]\right.\right.\right.
\end{array}\right\} \\
& +2.303\left(\frac{w_{1} w_{2}}{T}\right)\left(w_{1}-w_{2}\right)\left\{\begin{array}{l}
-1054.03+10.43 .54\left[\left(c_{1}-c_{2}\right)^{2}\right]+359.47\left[\left(E\left(e_{1}-e_{2}\right)^{2}\right]-1.20\left[\left(S\left(s_{1}-s_{2}\right)^{2}\right]\right.\right. \\
+30.26\left[\left(A\left(a_{1}-a_{2}\right)^{2}\right]-2.66\left[\left(B\left(b_{1}-b_{2}\right)^{2}\right]-0.16\left[\left(V\left(v_{1}-v_{2}\right)^{2}\right]\right.\right.\right.
\end{array}\right\} \\
& +2.303\left(\frac{w_{1} w_{2}}{T}\right)\left(w_{1}-w_{2}\right)^{2}\left\{\begin{array}{l}
2895.07-1913.07\left[\left(c_{1}-c_{2}\right)^{2}\right]-901.29\left[E\left(e_{1}-e_{2}\right)^{2}\right]-10.87\left[S\left(s_{1}-s_{2}\right)^{2}\right] \\
+24.62\left[A\left(a_{1}-a_{2}\right)^{2}\right]+9.79\left[B\left(b_{1}-b_{2}\right)^{2}\right]-24.38\left[V\left(v_{1}-v_{2}\right)^{2}\right]
\end{array}\right\}
\end{aligned}
$$

employing solubility of 48 drugs in 8 aqueous binary cosolvent mixtures at various temperatures which correlates the data with the overall MPD of $42.4 \%$ (100).

The main limitation of the Jouyban-AcreeAbraham models (Eqs. 62-65) is that the
Abraham solvent coefficients are not available for a number of pharmaceutically relevant cosolvents. To cover this point, another generally trained model based on Eq. 23 using Hansen solubility parameters was proposed as (101):

$$
\begin{aligned}
& \ln x_{\mathrm{m}, \mathrm{T}}=w_{1} \ln x_{1, \mathrm{~T}}+w_{2} \ln w_{2, \mathrm{~T}}+2.303\left(\frac{w_{1} w_{2}}{T}\right)\left\{\left(0.606 \delta_{\mathrm{p} 1}\left(\delta_{\mathrm{p} 2}-\delta_{\mathrm{p} 3}\right)^{2}+0.013 \delta_{\mathrm{h} 1}\left(\delta_{\mathrm{h} 2}-\delta_{\mathrm{h} 3}\right)^{2}\right\}\right. \\
& +2.303\left(\frac{w_{1} w_{2}}{T}\right)\left(w_{1}-w_{2}\right)\left\{-8.696 \delta_{\mathrm{h} 1}\left(\delta_{\mathrm{h} 2}-\delta_{\mathrm{h} 3}\right)^{2}+0.376 \delta_{\mathrm{p} 1}\left(\delta_{\mathrm{p} 2}-\delta_{\mathrm{p} 3}\right)^{2}+0.013 \delta_{\mathrm{h} 1}\left(\delta_{\mathrm{h} 2}-\delta_{\mathrm{h} 3}\right)^{2}\right. \\
& +2.303\left(\frac{w_{1} w_{2}}{T}\right)\left(w_{1}-w_{2}\right)^{2}\left\{9.277 \delta_{\mathrm{d} 1}\left(\delta_{\mathrm{d} 2}-\delta_{\mathrm{d} 3}\right)^{2}-0.461 \delta_{\mathrm{p} 1}\left(\delta_{\mathrm{p} 2}-\delta_{\mathrm{p} 3}\right)^{2}+0.017 \delta_{\mathrm{h} 1}\left(\delta_{\mathrm{h} 2}-\delta_{\mathrm{h} 3}\right)^{2}\right.
\end{aligned}
$$

where $\delta_{\mathrm{h} 1}, \delta_{\mathrm{p} 1}, \delta_{\mathrm{d} 1}, \delta_{\mathrm{h} 2}, \delta_{\mathrm{p} 2}, \delta_{\mathrm{d} 2}, \delta_{\mathrm{h} 3}, \delta_{\mathrm{p} 3}$ and $\delta_{\mathrm{d} 3}$ are the partial solubility parameters of the solutes, solvents 1 and 2. $\delta_{\mathrm{d}}$ is the energy from dispersion bonds between molecules, $\delta_{\mathrm{p}}$ is the energy from polar bonds between molecules, and $\delta_{\mathrm{h}}$ is the energy from hydrogen bonds between molecules.

\section{In silico models}

Solubility of anthrecene and pyrene in a number of non-aqueous ternary solvent mixtures was predicted using an in silico model reported in earlier papers (140-143). The Abraham model (14) was used to predict the solubility in the mono-solvents and the mixed solvent interaction terms of Eq. 62 was used to predict the solubility in solvent mixtures in which the obtained prediction errors were acceptable (143). Several attempts to provide an in silico model to predict drug solubility in binary solvents were not successful so far and more efforts should be made to achieve this valuable goal.

\section{CONCLUSION}

The accuracies of a number of cosolvency models were compared using 30 data sets of the solubility of drugs in aqueous binary solvent mixtures at a given temperature concerning the number of curve-fitting parameters and input data. The results showed that $\% \mathrm{Dev}$ for correlated solubility data varied from $22.3 \%$ (for CNIBS/R-K model with three constant terms) to $3.1 \%$ (for the same model with 7 constant terms) as was expected. Concerning a given number of constant terms for various models, the observed $\% \mathrm{Dev}$ were relatively the same for multi-linear models (63). This observation could be theoretically justified since all these models could be converted to GSM 
as discussed earlier (24). As a general conclusion, there is no full predictive model for solubility of drugs in mixed solvent systems. To provide such models, more comprehensive solubility database is required and researches are ongoing to provide such a big database. However, employing a minimum number of experimental data points for a given drug in a certain mixed solvent system, one may provide prediction tools with acceptable accuracy to save the time and cost of the experimental works in the pharmaceutical industry.

\section{ACKNOWLEDGMENT}

This work is dedicated to the memory of Professor Abbas Shafiee (sadly passed away in June 2016), Department of Medicinal Chemistry, Faculty of Pharmacy, Tehran University of Medical Sciences, Tehran, Iran, for his great efforts in establishment of postgraduate pharmaceutical sciences' studies in Iran.

\section{REFERENCES}

1. Jouyban A. Handbook of Solubility Data for Pharmaceuticals, CRC, Boca Raton, FL, USA, 2010.

2. Martinez F, Jouyban A, Acree Jr WE. Pharmaceuticals solubility is still nowadays widely studied everywhere. Pharm Sci, 23: 1-2, 2017.

3. Loftsson T, Brewster ME. Pharmaceutical applications of cyclodextrins: basic science and product development. J Pharm Pharmacol, 62: 1607-1621, 2010.

4. Simon DI, Brosius FC, Rothstein DM. Sulfadiazine crystalluria revisited: the treatment of Toxoplasma encephalitis in patients with acquired immunodeficiency syndrome. Arch Intern Med 150:2379-2384, 1990.

5. Eedara BB, Tucker IG, Zujovic ZD, Rades T, Price JR, Das SC. Crystalline adduct of moxifloxacin with trans-cinnamic acid to reduce the aqueous solubility and dissolution rate for improved residence time in the lungs. Eur $\mathrm{J}$ Pharm Sci, in press, 2019.

6. Ha ES, Kuk DH, Kim JS, Kim MS. Solubility of trans-resveratol in Transutol HP + water mixtures at different temperatures and its application to fabrication of nanosuspensions. J Mol Liq, 281: 344-351, 2019.

7. Jouyban A, Fakhree MAA, Shayanfar A. Solubility prediction methods for drug/drug like molecules. Recent Patents Chem Eng, 1: 220231, 2008.

8. Jouyban A, Fakhree MAA. In: Acree Jr WE (Ed) Toxicity and Drug Testing, Intech Co., New York, pp. 187-217, 2012.
9. Jouyban-Gharamaleki V, Rahimpour E, Acree Jr WE, Jouyban A. Smart systems for determination of drug's solubility. Drug Dev Ind Pharm, 45: 177-187, 2019.

10. Yalkowsky SH, Roseman T. In: Yalkowsky SH (Ed), Solubilization of Drugs by Cosolvents. Marcel Dekker, New York, pp. 91-134, 1981.

11. Ruckenstein E, Shulgin I. Solubility of drugs in aqueous solutions - Part 2: Binary nonideal mixed solvent. Int J Pharm, 260: 283-291, 2003.

12. Hildebrand JH. Solubility. XII. Regular solutions. J Am Chem Soc, 51: 66-80, 1929.

13. Adjei A, Newburger J, Martin A. Extended Hildebrand approach. Solubility of caffeine in dioxane-water mixtures. J Pharm Sci, 69: 659661, 1980.

14. Abraham $\mathrm{MH}$, Acree Jr WE. Partition coefficients and solubilities of compounds in the water-ethanol solvent systems. J Solution Chem, 40: 1279-1290, 2011.

15. Yalkowsky SH, Valvani SC. Solubility and partitioning I: Solubility of nonelectrolytes in water. J Pharm Sci, 69: 912-922, 1980.

16. Paruta AN, Sciarrone BJ, Lordi NG. Solubility of salicylic acid as a function of dielectric constant. J Pharm Sci, 53: 1349-1353, 1964.

17. Martin A, Wu PL, Adjei A, Lindstrom RE, Elworthy PH. Extended Hildebrand solubility approach and the $\log$ linear solubility equation. $\mathrm{J}$ Pharm Sci, 71: 849-856, 1982.

18. Martin A, Paruta AN, Adjei A. ExtendedHildebrand solubility approach: methylxanthines in mixed solvents. J Pharm Sci, 70: 1115-1120, 1981.

19. Bustamante P, Escalera B, Martin A, Selles E. A modification of the extended Hildebrand approach to predict the solubility of structurally related drugs in solvent mixtures. J Pharm Pharmacol, 45: 253-257, 1993.

20. Reillo A, Bustamante P, Escalera B, Jimanez MM, Selles E. Solubility parameter based methods for predicting the solubility of sulfapryidine in solvent mixtures. Drug Dev Ind Pharm, 21: 2073-2084, 1995.

21. Williams NA, Amidon GL. Excess free energy approach to the estimation of solubility in mixed solvent system. II. Ethanol-water mixtures. J Pharm Sci, 73: 14-18, 1984.

22. Khossravi D, Connors KA. Solvent effect on chemical processes. I: Solubility of aromatic and heterocyclic compounds in binary aqueousorganic solvents. J Pharm Sci, 81: 371-379, 1992.

23. Acree Jr WE. Mathematical representation of thermodynamic properties. Part II. Derivation of the combined nearly ideal binary solvent (NIBS)/Redlich-Kister mathematical representation from a two-body and three-body interactional mixing model. Thermochim Acta, 198: 71-79, 1992. 
24. Barzegar-Jalali M, Jouyban-Gharamaleki A. A general model from theoretical cosolvency models. Int J Pharm, 152: 247-250, 1997.

25. Jouyban-Gharamaleki A, Khaledi MG, Clark BJ. Calculation of electrophoretic mobilities in water-organic modifier mixtures in capillary electrophoresis. J Chromatogr A, 868: 277-284, 2000.

26. Jouyban A, Chan HK, Barzegar-Jalali M, Acree Jr WE. A model to represent solvent effects on the chemical stability of solutes in mixed solvent systems. Int J Pharm, 243: 167-172, 2002.

27. Jouyban A, Soltani S, Chan HK, Acree Jr WE. Modeling acid dissociation constant of analytes in binary solvents at various temperatures using Jouyban-Acree model. Thermochim Acta, 428: 119-123, 2005.

28. Jouyban A, Rashidi MR, Vaez-Gharamaleki Z, Matin AA, Djozan Dj. Mathematical representation of analyte's capacity factor in binary solvent mobile phases using JouybanAcree model. Pharmazie, 60: 827-829, 2005.

29. Jouyban A, Soltanpour Sh, Chan HK. A simple relationship between dielectric constant of mixed solvents with solvent composition and temperature. Int J Pharm, 269: 353-360. 2004.

30. Jouyban A, Fathi-Azarbayjani A, BarzegarJalali M, Acree Jr WE. Correlation of surface tension of mixed solvents with solvent composition. Pharmazie, 59: 937-941, 2004.

31. Jouyban A, Khoubnasabjafari M, VaezGharamaleki Z, Fekari Z, Acree Jr WE. Calculation of the viscosity of binary liquids at various temperatures using Jouyban-Acree model. Chem Pharm Bull, 53: 519-523, 2005.

32. Jouyban A, Fathi-Azarbayjani A, Khoubnasabjafari M, Acree Jr. WE. Mathematical representation of the density of liquid mixtures at various temperatures using Jouyban-Acree model. Indian J Chem A, 44: 1553-1560, 2005.

33. Jouyban A, Khoubnasabjafari M, Acree Jr WE. Modeling the solvatochromic parameter $\left(E_{T}^{N}\right)$ of mixed solvents with respect to solvent composition and temperature using JouybanAcree model. Daru, 14: 22-25, 2006.

34. Jouyban A, Soltani S, Khoubnasabjafari M, Acree Jr WE. Refractive index correlation of solvent mixtures at various temperatures. Asian J Chem, 18: 2037-2040, 2006.

35. Hasan M, Shirude DF, Hiray AP, Sawant AB, Kadam UB. Densities, viscosities and ultrasonic velocities of binary mixtures of methylbenzene with hexan-2-ol, heptan-2-ol and octan-2-ol at T $=298.15$ and $308.15 \mathrm{~K}$. Fluid Phase Equilib, 252: 88-95, 2006.

36. Khattab IS, Bandarkar F, Khoubnasabjafari M, Jouyban A. Density, viscosity, surface tension, and molar volume of propylene glycol + water mixtures from 293 to $323 \mathrm{~K}$. Arab J Chem, 10: S71-S75, 2017.

37. Shen Y, Zong S, Dang L, Wei H. Solubility and thermodynamics of probenecid-4,4'-azopyridine cocrystal in pure and binary solvents. J Mol Liq, in press, 2019.

38. Llinas A, Glen RC, Goodman JM. Solubility challenge: can you predict solubilities of 32 molecules using a database of 100 reliable measurements? J Chem Inf Model 48:12891303, 2008.

39. Hopfinger AJ, Esposito EX, Llinas A, Glen RC, Goodman JM. Findings of the challenge to predict aqueous solubility. J Chem Inf Model, 49: 1-5, 2008.

40. Eric S, Kalinic M, Popovic A, Makic H, Civic E, Bektasevic $M$. The importance of the accuracy of the experimental data for the prediction of solubility. J Serb Chem Soc, 74: 483-495, 2010.

41. Boobier S, Osbourn, Mitchell JBO. Can human experts predict solubility better than computers? J Cheminform, 9: 63, 2017.

42. Palmer DS, Mitchell JBO. Is experimental data quality the limiting factor in predicting the aqueous solubility of druglike molecules? Mol Pharm, 11: 2962-2972, 2014.

43. Yalkowsky SH, He Y. Handbook of Aqueous Solubility Data, CRC, Boca Raton, FL, USA, 2003.

44. www.scopus.com

45. van't Hoff. JH, L'équilibre chimique dans les systémes gazux ou dissous á L'état dilué. Arch. Néerl. Sci. Exact. Natur., 20: 239-302, 1886, cited in Int J Pharm, 18, 25-38, 1984.

46. Hildebrand $\mathrm{JH}$, The temperature dependence of the solubility of solid nonelectrolytes. J Chem Phys, 20: 190-191, 1952.

47. Grant DJW, Mehdizadeh M, Chow AHL, Fairbrother JE, Non-linear van't Hoff solubilitytemperature plots and their pharmaceutical interpretation. Int J Pharm, 18: 25-38, 1984.

48. Apelblat, A., Manzurola, E.: Solubilities of oacetylsalicylic, 4-aminosalicylic, 3,5dinitrosalicylic, and p-toluic acid, and magnesium-DL-aspartate in water from $\mathrm{T}=$ (278 to 348$)$ K. J Chem Thermodyn, 31: 8591,1999 .

49. Wang S, Chen X, Liu B, Du Y, Wang J. Temperature dependent solubility of sodium cyclamate in selected pure solvents and binary methanol + water mixed solvents. Fluid Phase Equilib, 390: 1-6, 2015.

50. Xie Y, Shi H, Du C, Cong Y, Zhao H. Solubility determination and modeling for 4,4'dihydroxydiphenyl sulfone in mixed solvents of (acetone, ethyl acetate, or acetonitrile) + methanol and acetone + ethanol from (278.15 to 313.15) K. J Chem Eng Data, 61: 3519-3526, 2016. 
51. Haq N, Siddiqui NA, Shakeel. Solubility and molecular interactions of ferulic acid in various (isopropanol + water) mixtures. J Pharm Pharmacol, 69: 1485-1494, 2017.

52. Ma Y, Cao Y, Yang Y, Li W, Shi P, Wang S, Tang, W. Thermodynamic analysis and molecular dynamic simulation of the solubility of vortioxetine hydrobromide in three binary solvent mixtures. J Mol Liq, 272, 676-688, 2018.

53. Feng X, Farajtabar A, Lin H, Chen G, Wang Z, Li X, Zhao H. Experimental solubility evaluation and thermodynamic analysis of biologically active D-tryptophan in aqueous mixtures of $\mathrm{N}, \mathrm{N}$-dimethylformamide and several alcohols. J Chem Thermodyn, 128, 3444, 2019.

54. Buchowski H, Ksiazczak A, Pietrzyk S. Solvent activity along a saturation line and solubility of hydrogen-bonding solids. J Phys Chem, 84: 975-979, 1980.

55. Jouyban A. Review of the cosolvency models for predicting solubility of drugs in watercosolvent mixtures. J Pharm Pharm Sci, 11: 3258, 2008.

56. Acree Jr WE, McCargar JW, Zvaigzne AI, Teng IL. Mathematical representation of thermodynamic properties. Carbazole solubilities in binary alkane + dibutyl ether and alkane + tetrahydropyran solvent mixtures. Phys Chem Liq, 23: 27-35, 1991.

57. Jouyban A, Khoubnasabjafari M, Chan HK, Acree Jr WE. Mathematical representation of solubility of amino acids in binary aqueousorganic solvent mixtures at various temperatures using the Jouyban-Acree model. Pharmazie 61: 789-792, 2006.

58. Jouyban-Gharamaleki A, Clark BJ, Acree Jr WE. Prediction of drug solubility in ternary solvent mixture. Drug Dev Ind Pharm, 26: 971973, 2000.

59. Jouyban-Gharamaleki, A, Clark, BJ, Acree Jr WE. Models to predict solubility in ternary solvents based on sub-binary experimental data. Chem Pharm Bull, 48, 1866-1871, 2000.

60. Soltanpour Sh, Jouyban A. Solubility of acetaminophen and ibuprofen in binary and ternary mixtures of polyethylene glycols 200 and 400, propylene glycol and water at $25^{\circ} \mathrm{C}$. Chem Eng Comm, 201: 1606-1619, 2014.

61. Jouyban-Gharamaleki A. The modified Wilson model and predicting drug solubility in watercosolvent mixtures. Chem Pharm Bull, 46: 1058-1061, 1998.

62. Jouyban A, Chew NYK, Chan HK, Sabour M, Acree Jr WE. A unified cosolvency model for calculating solute solubility in mixed solvents. Chem Pharm Bull, 53: 634-637, 2005.

63. Jouyban-Gharamaleki A, Valaee L, BarzegarJalali M, Clark BJ, Acree Jr WE. Comparison of various cosolvency models for calculating solute solubility in water-cosolvent mixtures. Int J Pharm, 177: 93-101, 1999.

64. Tarantino R, Bishop E, Chen F-C, Iqbal K, Malick W. N-Methyl-2-pyrrolidone as a cosolvent: Relationship of cosolvent effect with solute polarity and the presence of protondonating groups on model drug compounds. J Pharm Sci, 83: 1213-1216, 1994.

65. Jouyban-Gharamaleki A, York P, Hanna M, Clark BJ. Solubility prediction of salmeterol xinafoate in water-dioxane mixtures. Int $\mathrm{J}$ Pharm, 216: 33-41, 2001.

66. Ochsner AB, Belloto Jr RJ, Sokoloski TD. Prediction of xanthine solubilities using statistical techniques. J Pharm Sci, 74: 132-135, 1985.

67. Barzegar-Jalali M, Hanaee J. Model for solubility estimation in mixed solvent systems. Int J Pharm, 109: 291-295, 1994.

68. Barzegar-Jalali M, Jouyban-Gharamaleki A. Models for calculating solubility in binary solvent systems. Int J Pharm, 140: 237-246, 1996.

69. Jouyban A, Romero S, Chan HK, Clark BJ, Bustamante P. A cosolvency model to predict solubility of drugs at several temperatures from a limited number of solubility measurements. Chem Pharm Bull, 50: 594-599, 2002.

70. Shakeel F, Bhat MA, Haq N, Fathi-Azarbayjani A, Jouyban A. Solubility and thermodynamic parameters of a novel anti-cancer drug (DHP-5) in polyethylene glycol $400+$ water mixtures. J Mol Liq, 229: 241-245, 2017.

71. Jouyban-Gharamaleki A, Acree Jr WE. Comparison of models for describing multiple peaks in solubility profiles. Int J Pharm, 167: 177-182, 1998.

72. Jouyban A, Acree Jr WE. Mathematical derivation of the Jouyban-Acree model to represent solute solubility data in mixed solvents at various temperatures. J Mol Liq, 256: 541-547, 2018.

73. Jouyban A, Clark BJ. Describing solubility of polymorphs in mixed solvents by CNIBS/R-K equation. Pharmazie, 57: 861-862, 2002.

74. Jouyban A, Shayanfar A, Acree Jr WE. Solubility prediction of polycyclic aromatic hydrocarbons in non-aqueous solvent mixtures. Fluid Phase Equilib, 293: 47-58, 2010.

75. Jouyban A, Acree Jr WE, Martinez F. Modelling the solubility and preferential solvation of gallic acid in cosolvent + water mixtures. J Mol Liq, 224: 502-506, 2016.

76. Vahdati S, Shayanfar A, Hanaee J, Martinez F, Acree Jr WE, Jouyban A. Solubility of carvedilol in ethanol + propylene glycol mixtures at various temperatures. Ind Chem Eng Res, 52: 16630-16636, 2013.

77. Yang W, Wu K, Hu Y, Zhang T, Guo Q, Yang S, Shi Yi. Korean J Chem Eng, 32: 1158-1163, 2015. 
78. Sun H, Liu B, Liu P, Zhang J, Wang Y, Solubility of fenofibrate in different binary solvents: experimental data and results of thermodynamic modeling. J Chem Eng Data, 61: 3177-3183, 2016.

79. Jouyban A, Martinez F, Acree Jr WE. Correct derivation of a combined version of the Jouyban-Acree and van't Hoff model and some comments on "Determination and correlation of the solubility of myricetin in ethanol and water mixtures from 288.15 to $323.15 \mathrm{~K}$ ". Phys Chem Liq, 55: 131-140, 2017.

80. Jouyban A, Martinez F, Acree Jr WE. Correct derivation of cosolvency models and some comments on "Solubility of fenofibrate in different binary solvents: Experimental data and results of thermodynamic modelling". J Chem Eng Data, 62: 1153-1156, 2017.

81. Cong Y, Du CB, Wang J, Zhao HK. Determination and thermodynamic modelling for 2-methyl-6-nitroaniline solubility in binary solvent mixtures of ethyl acetate + (methanol, ethanol, n-propanol and isopropanol). J Chem Thermodyn, 105: 404-413, 2017.

82. Wang L, Sun J, Zhang H, Shen Z, Liu G. Solubility and thermodynamic analysis of methyleneaminoacetonitrile in binary solvents from $\mathrm{T}=(278.15$ to 313.15$) \mathrm{K}$. J Mol Liq, 283: 462-471, 2019.

83. Dadmand S, Kamari F, Acree Jr WE, Jouyban A. Solubility prediction of drugs in binary solvent mixtures at various temperatures using a minimum number of experimental data points, AAPS PharmSciTech 20: 10, 2019.

84. Zhou Z, Qu Y, Wang J, Wang S, Liu J, Wu M. Measurement and correlation of solubilities of (Z)-2-(2-aminothiazol-4-yl)-2-

methoxyiminoacetic acid in different pure solvents and binary mixtures of water + (ethanol, methanol, or glycol). J Chem Eng Data, 56: 1622-1628, 2011.

85. Ma H, Qu Y, Zhou Z, Wang S, Li L. Solubility of thiotriazinone in binary solvent mixtures of water + methanol and water + ethanol from $(283$ to 330) K. J Chem Eng Data, 57: 2121-2127, 2012.

86. Mirheydari SN, Barzegar-Jalali M, Acree Jr WE, Shekaari H, Shayanfar A, Jouyban A. Comparison of the solubility models for correlation of drug solubility in ethanol + water binary mixtures, J Solution Chem, 48: 10791104, 2019.

87. Jouyban A, Chan HK, Chew NYK, Khoubnasabjafari M, Acree Jr WE. Solubility prediction of paracetamol in binary and ternary solvent mixtures using Jouyban-Acree model. Chem Pharm Bull, 54: 428-431, 2006.

88. Soltanpour Sh, Jouyban A. Solubility of lamotrigine in binary and ternary mixtures of Nmethyl pyrrolidone and water with polyethylene glycols 200, 400, and 600 at 298.2 K. J Mol Liq, 180: 1-6, 2013.

89. Jouyban A, Acree Jr WE. Comments on "Prediction of drug solubility in lipid mixtures from the individual ingredients". AAPS PharmSciTech, 15: 83-85, 2014.

90. Jouyban A, Acree Jr WE. In silico prediction of drug solubility in water-ethanol mixtures using Jouyban-Acree model. J Pharm Pharm Sci, 9: 262-269, 2006.

91. Jouyban A. Solubility prediction of drugs in water-PEG 400 mixtures. Chem Pharm Bull, 54: 1561-1566, 2006.

92. Jouyban A. In silico prediction of drug solubility in water-dioxane mixtures using Jouyban-Acree model. Pharmazie, 62: 46-50, 2007.

93. Jouyban A. Prediction of drug solubility in water-propylene glycol mixtures using JouybanAcree model. Pharmazie, 62: 365-367, 2007.

94. Khoubnasabjafari M, Shayanfar A, Martinez F, Acree Jr WE, Jouyban A. Generally trained models to predict solubility of drugs in carbitol + water mixtures at various temperatures. J Mol Liq, 219, 435-438, 2016.

95. Barzegar-Jalali M, Rahimpour E, Martinez F, Shayanfar A, Jouyban A. Generally trained models to predict drug solubility in methanol + water mixtures. J Mol Liq, 264, 631-644, 2018.

96. Rahimpour E, Barzegar-Jalali M, Shayanfar A, Jouyban A. Generally trained models to predict drug solubility in N-methyl-2-pyrrolidone + water mixtures at various temperatures. J Mol Liq, 254, 34-38, 2018.

97. Hatefi A, Jouyban A, Mohammadian E, Acree Jr WE, Rahimpour E. Prediction of paracetamol solubility in cosolvency systems at different temperatures. J Mol Liq, 273: 282-291, 2019.

98. Mohamadian E, Barzegar-Jalali M, Rahimpour E. Solubility prediction of lamotrigine in cosolvency systems using Abraham and Hansen solvation parameters. J Mol Liq, 276: 675-679, 2019.

99. Jouyban-Gharamaleki A. Chameleonic effect and some models for predicting drug solubility in solvent mixtures. Chem Pharm Bull, 45: 1383-1384, 1997.

100. Jouyban A, Soltanpour Sh, Soltani S, Tamizi E, Fakhree MAA, Acree Jr WE. Prediction of drug solubility in mixed solvents using computed Abraham parameters. J Mol Liq, 146: 82-88, 2009.

101. Jouyban A, Shayanfar A, Panahi-Azar V, Soleymani J., Yousefi BH, Acree Jr WE, York P. Solubility prediction of drugs in mixed solvents using partial solubility parameters. J Pharm Sci, 100: 4368-4382, 2011.

102. Ali HSM, York P, Blagden N, Khoubnasabjafari M, Acree Jr WE, Jouyban A. Solubility of salbutamol and salbutamol sulphate in ethanol + 
water mixtures at $25^{\circ} \mathrm{C}$. J Mol Liq, 173: 62-65, 2012.

103. Mabhoot A, Jouyban A. Solubility of sodium phenytoin in ethanol + water mixtures at various temperatures. Chem Eng Comm, 203: 10091012, 2016.

104. Jouyban A, Panahi-Azar V, Fakhree MAA, Ahmadian S. Solubilization of clonazepam, diazepam and lamotrigine using ethanol and sodium dodecyl sulfate. J Solution Chem, 43: 1997-2009, 2014.

105. Jouyban A, Panahi-Azar V, Fakhree MAA, Ahmadian S. Solubility of phenytoin in aqueous mixtures of ethanol and sodium dodecyl sulfate at 298 K, Rev Colom Cien Quím Farm, 43: 153$161,2014$.

106. Soltani N, Shaynafar A, Djozan Dj, Jouyban A. Solubility of three basic drugs in propylene glycol + water mixtures in the presence of $\beta$ cyclodextrin. J Drug Deliv Sci Technol, 23: 187-190, 2013.

107. Mabhoot A, Jouyban A. Solubility of sodium phenytoin in propylene glycol + water mixtures in the presence of $\beta$-cyclodextrin, Pharm Sci, 21: 152-156, 2015.

108. Jouyban A, Sajed-Amin S, Panahi-Azar V. Solubility of atenolol, amiodarone $\mathrm{HCl}$ and lamotrigine in polyethylene glycol $200+$ water mixtures in the presence of $\beta$-cyclodextrin. J Drug Del Sci Technol, 24: 543-547, 2014.

109. Fathi Azarbayjani A, Sajedi-Amin S, PanahiAzar V, Asadpour-Zeynali K, Jouyban A. Cosolublilization of lamotrigine by complexation and micellization in binary solvent mixtures. Chem Eng Res Design, 105: 64-70, 2016.

110. Soltanpour Sh, Acree Jr WE, Jouyban A. Effect of different concentrations of poly(vinyl pyrrolidone) on the solubility of lamotrigine and diazepam in ethanol + water mixtures at 298.2 K. J Chem Eng Data, 55: 570-573, 2010.

111. Soltanpour Sh, Jouyban A. Solubility of lamotrigine and diazepam in propylene glycol + water + carboxymethyl cellulose mixtures at 298.2 K. J Chem Eng Data, 55: 2890-2893, 2010.

112. Azmi R, Salamat-Ahangari R, Soleymani S, Jouyban A. Solubility of acetaminophen in ethanol + water $+\mathrm{NaCl}$ mixtures at various temperatures. Chem Eng Comm, 203: 471-475, 2016.

113. Panahi-Azar V, Shayanfar A, Martinez F, Acree Jr WE, Jouyban A. Thermodynamic studies of fluphenazine decanoate solubility in propylene glycol + water mixtures and correlation with the Jouyban-Acree model. Fluid Phase Equilib, 308: 72-77, 2011.

114. Soltanpour Sh, Jouyban A. Solubility of acetaminophen and ibuprofen in polyethylene glycol 600, propylene glycol and water mixtures at $25^{\circ} \mathrm{C}$. J Mol Liq, 155: 80-84, 2010.
115. Machatha SG, Bustamante P, Yalkowsky SH. Deviation from linearity of drug solubility in ethanol/water mixtures. Int J Pharm, 283: 83-88, 2004.

116. Machatha SG, Yalkowsky SH. Bilinear model for the prediction of drug solubility in ethanol/water mixtures. J Pharm Sci, 94: 27312734, 2005.

117. Machatha SG, Yalkowsky SH. Estimation of the ethanol/water solubility profile from the octanol/water partition coefficient. Int J Pharm, 286: 111-115, 2004.

118. McCargar JW, Acree Jr WE.Thermochemical investigations of associated solutions: Effect of the inert cosolvent on solute-solvent association constants calculated from solubility measurements. Phys Chem Liq, 17: 123-138, 1987.

119. Acree Jr WE, Zvaigzne AI. Thermodynamic properties of non-electrolyte solutions. Part 4. Estimation and mathematical representation of solute activity coefficients and solubilities in binary solvents using the NIBS and modified Wilson equations. Thermochim Acta, 178: 151167, 1991.

120. Acree Jr WE, McCargar JW, Zvaigzne AI, Teng IL. Mathematical representation of thermodynamic properties. Carbazole solubilities in binary alkane + dibutyl ether and alkane + tetrahydropyran solvent mixtures. Phys Chem Liq, 23: 27-35, 1991.

121. Acree Jr WE, Tucker SA. Thermochemical investigations of associated solutions: 16 . Comparison of the extended NIBS model and mobile order theory for solubility in systems containing solute-solvent complexation. Int $\mathrm{J}$ Pharm, 101: 199-207, 1994.

122. Acree Jr WE, Zvaigzne AI. Thermochemical investigations of hydrogen bonded solutions. Part 5. Development of predictive equations for the solubility of anthracene in binary alcohol + alcohol mixtures based upon mobile order theory. Fluid Phase Equilib, 99: 167-183, 1994.

123. Myrdal PB, Manka AM, Yalkowsky SH. AQUAFAC: Aqueous functional group activity coefficients: Application to the estimation of aqueous solubility. Chemosphere, 30: 16191637, 1995.

124. Jouyban-Gharamaleki A, Barzegar-Jalali M, Acree $\mathrm{Jr}$ WE. Solubility correlation of structurally related drugs in binary solvent mixtures. Int J Pharm, 166: 205-209, 1998.

125. Jouyban-Gharamaleki A, Dastmalchi S, Chan HK, Hanaee J, Javanmard A, Barzegar-Jalali M. Solubility prediction for furosemide in watercosolvent mixtures using the minimum number of experiments. Drug Dev Ind Pharm, 27: 577583, 2001.

126. Barzegar-Jalali M, Jouyban-Gharamaleki A, Hanaee J, Chokhachizadeh-Moghaddam MH. Comparison of double log-log, mixture 
response-surface and combined NIBS/RedlichKister solubility models. Int J Pharm, 144: 127130, 1996.

127. Jouyban A, Chan HK, Romero S, Khoubnasabjafari M, Bustamante P. Solubility prediction in water-ethanol mixtures based on excess free energy approach using minimum number of experimental data. Pharmazie, 59: 117-120, 2004.

128. Jouyban A, Khoubnasabjafari M, Chan HK, Clark BJ, Acree Jr WE. Solubility prediction of anthracene in mixed solvents using a minimum number of experimental data. Chem Pharm Bull, 50: 21-25, 2002.

129. Fakhree MAA, Delgado D, Martinez F, Jouyban A. The importance of dielectric constant for drug solubility prediction in binary solvent mixture: Electrolyte and zwitterions in ethanol + water. AAPS PharmSciTech, 11: 1726-1729, 2010 .

130. Abbasi M, Martinez F, Jouyban A. Prediction of deferiprone solubility in aqueous mixtures of ethylene glycol, propylene glycol and polyethylene glycol 400 at various temperatures. J Mol Liq, 197: 171-175, 2014.

131. Jouyban-Gharamaleki V, Jouyban-Gharamaleki K, Soleymani J, Acree Jr WE, Jouyban A. Solubility determination of tris(hydroxymethyl)aminomethane in water + methanol mixtures at various temperatures using a laser monitoring technique. J Chem Eng Data, 59: 2305-2309, 2014.

132. Jouyban A, Chew NYK, Chan HK, Khoubnasabjafari M, Acree Jr WE. Solubility prediction of salicylic acid in water-ethanolpropylene glycol mixtures using Jouyban-Acree model, Pharmazie. 61: 318-321, 2006.

133. Jouyban A, Martinez F. Solution thermodynamics and preferential solvation of hesperidin in aqueous cosolvent mixtures of ethanol, isopropanol, propylene glycol, and npropanol. Phys Chem Liq, 57: 432-444, 2019.

134. Farjami A, Jouyban A. Lamotrigine solubility in some nonaqueous solvent mixtures at $298.2 \mathrm{~K}$. J Chem Eng Data, 60: 2490-2494, 2015.
135. Li A. Predicting cosolvency. 3. Evaluation of the extended log-linear. Ind Eng Chem Res, 40: 5029-5035, 2001.

136. Jouyban A, Fakhree MAA, Hamzeh-Mivehroud M, Acree Jr WE. Modelling the deviations of solubilities in water-dioxane mixtures from predicted solubilities by the Jouyban-Acree model. J Drug Del Sci Technol, 17: 359-363, 2007.

137. Jouyban A, Fakhree MAA, Ghafourian T, Saei AA, Acree Jr WE. Deviations of drug solubility in water-cosolvent mixtures from the JouybanAcree model. Effect of solute structure. Pharmazie, 63: 113-121, 2008.

138. Jouyban A, Acree Jr WE. Prediction of drug solubility in ethanol-ethyl acetate mixtures at various temperatures using the Jouyban-Acree model,. J Drug Del Sci Technol,17: 159-160, 2007.

139. Jouyban A, Khoubnasabjafari M, Martinez F. A model to predict the solubility of drugs in ethanol + propylene glycol mixtures at various temperatures. Bulg Chem Comm, 47: 800-803, 2015.

140. Jouyban A, Khoubnasabjafari M, Acree Jr WE. Predicting solubility of anthracene in nonaqueous solvent mixtures using a combination of Jouyban-Acree and Abraham models. Chem Pharm Bull, 54: 1124-1130, 2006.

141. Jouyban A, Khoubnasabjafari M, Acree Jr WE. Solubility prediction of anthracene in nonaqueous solvent mixtures using a combination of Jouyban-Acree and Abraham models. Can J Chem, 84: 874-885, 2006.

142. Jouyban A, Acree Jr WE. Solubility prediction in non-aqueous binary solvents using a combination of Jouyban-Acree and Abraham models. Fluid Phase Equilib, 249: 24-32, 2006.

143. Jouyban A, Khoubnasabjafari M, Hamidi AA, Acree Jr WE. Ab initio solubility prediction of non-electrolytes in ternary solvents using a combination of Jouyban-Acree and Abraham models. Asian J Chem, 20, 3413-3437, 2008. 